\title{
TRANSFORMAÇÕES NO JORNALISMO DIÁRIO PARANAENSE: O CASO BEM PARANÁ/JORNAL DO ESTADO
}

\author{
Maria Zaclis Veiga Ferreira' ${ }^{1}$ \\ Elza Aparecida de Oliveira Filha ${ }^{2}$ \\ Eliane Basílio de Oliveira ${ }^{3}$
}

\begin{abstract}
Resumo
Este texto apresenta um relato das transformações ocorridas nas rotinas de produção, nas relações de trabalho e na organização da redação do jornal curitibano Bem Paraná/Jornal do Estado, na última década. A partir de entrevistas realizadas com profissionais e de observações no site da empresa, são historiadas as principais alterações nos processos de trabalho e detalhados os impactos destas transformações em dois âmbitos: de um lado, o volume e o formato das informações disponibilizadas aos leitores e/ou internautas e, de outro, o ritmo e as condições de desempenho profissional dos jornalistas.
\end{abstract}

Palavras-chave: Jornalismo impresso, jornalismo digital, trabalho, reestruturação produtiva.

\begin{abstract}
The main goal of this paper is to make an account about the transformations in the production routines, work relations and organization in the daily newspaper Bem Paranál Jornal do Estado, based in Curitiba, in the last decade. It tells the main transformations in the working process and the consequences of those changes into two strands: the information quantity and its formats offered to readers and internet users, and the rhythm and conditions of work for journalists' professional performance. Interviews were used as the main source of information.
\end{abstract}

Keywords: Printed journalism, digital journalism, work, productive restructuring.

\section{Introdução}

O portal Bem Paraná foi criado em 2006, utilizando a mesma estrutura da redação do Jornal do Estado (JE). Em circulação desde 1983, o JE disponibilizava suas edições na internet, mas não agregava novos conteúdos. Depois da criação do portal, o noticiário foi expandido e estabelecidas novas editorias, com foco na cobertura local. De acordo com a jornalista Josianne Ritz, chefe de redação do impresso e do portal, o nome Bem Paraná foi aceito pelo público, e a audiência do site tem mantido uma linha de crescimento, tendo alcançado 2,4 milhões de páginas visualizadas em abril de 2014, contra 951 mil no mesmo período do ano anterior. Em

\footnotetext{
${ }^{1}$ Doutora e Ciências da Informação (Universidade Fernando Pessoa, Portugal), mestre em Multimeios (Unicamp), bacharel em Jornalismo (UEPG). Professora e coordenadora do curso de Jornalismo da Universidade Positivo. Email: jornalismo@up.com.br.

2 Doutora em Ciências da Comunicação (Unisinos), mestre em Sociologia (UFPR), bacharel em Jornalismo (UFPR) com mais de 20 anos de atuação na imprensa diária. Professora do bacharelado em Comunicação Organizacional da Universidade Tecnológica Federal do Paraná (UTFPR). E-mail: elzaap@ hotmail.com.

${ }^{3}$ Mestre em Educação (UFPR), socióloga (PUC-PR), professora do curso de Jornalismo da Universidade Positivo e do curso de Publicidade e Propaganda do Centro Universitário Curitiba. E-mail: lilibasilio@ yahoo.com.br.
} 
junho de 2013, quando completou 30 anos de circulação, o Jornal do Estado mudou de nome: passou a se chamar Bem Paraná, assim como o portal, mantendo como slogan, logo abaixo do título, a expressão “O Jornal do Estado".

As transformações vivenciadas pelos jornalistas que integram a redação do portal Bem Paraná e do impresso Jornal do Estado são representativas de um conjunto de mudanças que afetaram a produção jornalística nas últimas décadas. De acordo com Fígaro (2013, p.4), "Os desafios que os jornalistas enfrentam no exercício profissional são grandes: vínculos empregatícios precários, baixos salários, extensas jornadas de trabalho, exigências de atualização constante no uso de ferramentas digitais de prospecção de informações, de apuração e edição".

Na sequência, este texto vai apresentar relatos de jornalistas que trabalham na redação do Bem Paraná/Jornal do Estado discutindo as mudanças ocorridas nos últimos anos, tomando como base as condições de trabalho e a visão dos profissionais acerca da informação jornalística e sua transformação a partir do advento e popularização da internet. As falas dos profissionais serão complementadas com enfoques teóricos, entre outros, de Sousa (2002), Breed (1993) e Fígaro (2013).

\section{Jornal do Estado / Bem Paraná}

Com 31 anos de circulação e "entre nove e dez mil" exemplares de tiragem diária, o jornal Bem Paraná está buscando "se reinventar para sobreviver", de acordo com a chefe de redação Josienne Ritz ${ }^{4}$. Este processo de reinvenção não poupou sequer o nome da publicação, que se chamava Jornal do Estado até um ano atrás. "Mas qual era o Estado? Ficava uma publicação sem identidade ou sendo confundida com o jornal $O$ Estado do Paraná, que circulou até recentemente", acrescentou Ritz, referindo-se ao diário que deixou de circular em Curitiba em $2011^{5}$. O fato de o jornal impresso assumir o nome do site é um acontecimento inusitado, que não tem registro semelhante, pelo menos no Paraná. O balanço das mudanças é favorável:

Os resultados estão sendo positivos, alteramos o projeto gráfico do impresso, seguindo o modelo do online, e ficou mais leve. Estamos tentando mudar o foco do jornal, que sempre foi muito sisudo, centrado no noticiário político e escrito para um público de

\footnotetext{
${ }^{4}$ Entrevista concedida às autoras no dia 30 de maio de 2014 na redação do jornal, em Curitiba.

${ }^{5}$ O jornal $O$ Estado do Paraná foi fundado em 1951 para dar sustentação ao então governador Bento Munhoz da Rocha Neto, que enfrentava oposição de todos os periódicos em circulação na capital. Em 1962, foi vendido para Paulo Pimentel, então secretário da Agricultura, e que chegou ao governo do Estado quatro anos depois, usando a estrutura de seus veículos de comunicação, entre os quais o jornal, para ampliar sua campanha (OLIVEIRA FILHA, 2007). O jornal, que continuava como propriedade de Pimentel, encerrou as edições impressas em fevereiro de 2011, manteve-se na internet durante mais alguns meses, mas acabou extinto com a venda de seus direitos e acervo ao Grupo Paranaense de Comunicação (GRPCOM).
} 
30 a 60 anos. A proposta agora é que o impresso acompanhe o site, com informações destinadas a um público de 8 a 80 anos e com caráter mais de variedades (RITZ, 2014).

A chefe de redação defendia a mudança do nome do jornal há pelo menos três anos, mas considerava difícil a direção da empresa aceitar. "Até que eles disseram: o que temos a perder? E aceitaram a alteração numa busca mesmo de salvar o jornal” (RITZ, 2014). O número de assinantes do impresso não sofreu alterações ainda, mas a expectativa é que as mudanças impactem também as vendas de assinaturas: "São cerca de mil assinantes hoje, concentrados em órgão públicos e empresas, mas queremos que as pessoas passem a comprar o jornal a partir da leitura do site", afirmou Ritz, lembrando que o Bem Paraná é um dos poucos veículos paranaenses que continua disponibilizando gratuitamente online a íntegra da edição impressa.

A migração da informação jornalística para a plataforma digital - especialmente a notícia, entregue aos leitores sem um trabalho mais aprofundado em busca de causas e consequências - é uma tendência mundial a partir do início do século XXI.

\footnotetext{
As mudanças nos processos e rotinas produtivas, a concorrência global e as novas demandas dos consumidores têm profundas implicações para os profissionais do setor da comunicação. Implicações que vão do campo ético-profissional ao cultural e pessoal [...]. Está em jogo que tipo de democracia quer-se construir, pois o direito à informação é o alicerce de uma sociedade democrática (FÍGARO, 2013, p. 12).
}

A autora apresenta uma contradição inerente ao jornalismo. Seu surgimento, no século XVII e expansão significativa no século XIX, está relacionado à luta pela liberdade de expressão, mas, ao mesmo tempo, representa os interesses privados. "É uma narrativa de urbanidade, da pólis, do cidadão e da cidadania, mas delimitada pelos valores do liberalismo econômico" (FÍGARO, 2013, p. 9).

No século XX, o jornalismo se profissionaliza, voltando-se mais abertamente ao mercado e ao lucro. Cinco empresas de comunicação concentram 50\% das receitas publicitárias no mundo todo. "No Brasil, os dados da pesquisa Perfil da Economia da Cultura, realizada pelo IBGE, 2003-2005, corroboram a relevância e a especificidade do setor da economia da cultura, bem como a tendência de concentração" (idem).

Pesquisas mostram que a internet só aumentou a concentração. No Brasil, cinco redes de TV privadas detêm a fatia mais importante da comunicação. "Com o cenário de expansão do capitalismo financeiro e de transformações econômicas e tecnológicas, o jornalismo ganha maior importância para os negócios" (FÍGARO, 2013, p. 11), e jornalismo perde espaço para as áreas comerciais. 
Em Curitiba, onde circula o Bem Paraná, esta realidade é palpável: nos últimos anos, três jornais impressos deixaram de existir: O Estado do Paraná, Diário Popular e Correio de Notícias. Hoje, o Grupo Paranaense de Comunicação (GRPCOM) exerce praticamente o monopólio da produção e distribuição de informação jornalística na medida em que edita os diários de maior circulação, Gazeta do Povo e Tribuna do Paraná - contando com a "concorrência tímida" do Bem Paraná e do Indústria e Comércio, jornal voltado para o noticiário econômico - e ainda controla os principais portais de notícias: gazetadopovo.com e paranaonline.com ${ }^{6}$.

Para competir, de alguma maneira, com o GRPCOM, ao falar sobre as mudanças implementadas no Bem Paraná, Ritz indica que algumas novidades estão a caminho, como um caderno de programação cultural que circulará encartado na edição de sexta-feira; o suplemento Bem Feito, com foco no consumidor e no jornalismo de serviço e o encarte semanal Bem na Segunda, destinado ao noticiário esportivo e policial, com um balanço dos acontecimentos do final de semana.

Esta última iniciativa, cujo projeto gráfico está concluído, foi possibilitada por uma parceria nascida também no site, evidenciando a importância no jornalismo online. Em função da escassez de pessoal na redação, e por uma opção editorial, o Jornal do Estado nunca ostentou uma cobertura policial significativa. As notícias desta área eram publicadas na editoria geral e, mesmo na internet, a cobertura seguia restrita até que, no ano passado, o Bem Paraná passou a hospedar o blog Plantão 190, produzido pelo repórter cinematográfico e fotográfico João Carlos Frigério, que trabalha para programas policiais da Rede Massa (empresa de televisão local, retransmissora do Sistema Brasileiro de Televisão, SBT). Com dezenas de milhares de seguidores nas redes sociais, Frigério tem uma extensa lista de fontes nos meios policiais e fora deles, garantindo um noticiário ágil e atualizado.

"Ele tinha um blog muito acessado, produzia muito material, mas não sabia como ganhar dinheiro na internet. Agora está sendo remunerado pelo site, embora ainda não no nível que gostaríamos, mas elevou nossas visualizações", relatou a chefe de redação, acrescentando que a principal modalidade de pagamento dos anúncios no portal Bem Paraná se dá por contagem de milhares de acessos.

Olhando o panorama geral da imprensa paranaense - e mesmo brasileira - Ritz percebe que os sites têm muita leitura, alguns consolidaram suas marcas, mas ainda não oferecem uma rentabilidade satisfatória. Para ela, a publicidade on line, embora receba maiores fatias do

\footnotetext{
${ }^{6}$ O GRPCOM possui ainda duas emissoras de rádio e duas de televisão em Curitiba; no interior do Paraná são outras sete emissoras, todas repetidoras da Rede Globo de Televisão.
} 
investimento das empresas a cada ano, não está totalmente consolidada. E cita como exemplo o próprio carro-chefe do segmento comercial do jornal impresso Bem Paraná - o mesmo que sustentou o Jornal do Estado por três décadas: a publicação de editais públicos e balanços de empresas comerciais que, pela legislação brasileira, são obrigatoriamente feitos em meio impresso. "Por isso existe um lobby violento no Congresso Nacional para que esta lei não seja alterada, pois seria o fim definitivo dos impressos", acrescentou a chefe de redação.

\section{Condições de Trabalho}

De uma maneira unânime, os jornalistas da redação do Bem Paraná reclamam da falta de pessoal e do acúmulo de funções. São sete profissionais de texto, além da chefe de redação, quatro dos quais são editores (de geral, economia, política/Brasil, esporte e cultura - esta última editoria é responsabilidade da chefe de redação, Josianne Ritz, que acumula os cargos). Apenas as editorias de esporte e geral contam, cada uma, com um repórter que tem condições de sair para a rua e apurar algum assunto. As demais editorias são fechadas com trabalho exclusivo dos editores que também fazem, eventualmente, alguma reportagem externa. A maior parte do material publicado vem de agências de notícias ou de assessorias de imprensa. Este quadro se encaixa na expressão empregada por Fígaro (2013, p. 89), que denomina a prática como "imprensa sentada": "A informação chega ao veículo, o jornalista não sai em busca dela. É comum a fonte receber um contato do jornalista e, ao aceitar dar entrevista, receber por e-mail a lista de perguntas a responder. Com isso, cresceu também a força das assessorias de imprensa para fazer o fato chegar ao veículo".

Alguns assuntos, mais raros no Bem Paraná, são apurados por telefone e produzidos na redação. A exceção fica por conta da editoria de política que tem um índice maior de produção própria quando as temáticas são relativas ao Paraná ou a Curitiba, pois o editor, Ivan Santos, é também responsável pelo blog Política em Debate, igualmente hospedado no portal Bem Paraná. Além dos quatro editores, completam o quadro do impresso, dois fotógrafos e quatro diagramadores.

Todos os editores do impresso cuidam também do site, fazem parte das escalas de plantões para atualizar o portal nos finais de semana e postam no portal praticamente tudo o que produzem sem alterações ${ }^{7}$. No Bem Paraná online trabalham ainda um jornalista que faz a atualização do noticiário no período da manhã; dois estagiários estudantes de jornalismo, à tarde, e um web designer. Este quadro reduzido de funcionários e a obrigatoriedade de

\footnotetext{
${ }^{7}$ Nos finais de semana, muitos plantonistas postam a partir de suas próprias residências e não vão até a redação.
} 
cumprimento de variadas funções vão ao encontro dos resultados de uma pesquisa conduzida pelo grupo de estudos sobre o mundo do trabalho jornalístico da Universidade de São Paulo desde 2008: "O mercado de trabalho quer um profissional multiplataforma e polivalente. Dele é exigido que tenha domínio dos mais variados meios e linguagem, assumindo funções desempenhadas antes por outros profissionais (editores, revisores, repórteres, diagramadores, pauteiros" (FÍGARO, 2013, p. 15).

Mario Akira Hisatorm ${ }^{8}$, editor de geral do Bem Paraná, afirma que trabalha a cobertura no limite: "É o possível para a realidade do jornal no momento. Precisa-se de uma equipe para poder separar e definir as funções. É complicado dividir o repórter com o site que é o carrochefe do jornal; a prioridade deles é cuidar do site. Não posso sobrecarregar o repórter com muitas matérias, normalmente é uma ou duas matérias especiais por semana. O ideal seria que ele trabalhasse com o factual, ter uma equipe direcionada para isso, o que já seria uma questão de investimento do jornal."

Segundo o editor, a falta de profissionais, de recursos e a pressão do relógio implicam diretamente na produção e no resultado final do trabalho. Ele também comentou sobre o que denomina como o "grande e grave" problema da imprensa brasileira:

\begin{abstract}
Os jornais hoje têm um alinhamento político determinado, a imprensa é assim, percebe-se claramente quem é a favor do quê. O Jornal do Estado [Bem Paraná] não foge à regra: posições políticas definidas que precisam ser seguidas em detrimento de outras prerrogativas da nossa profissão. A imprensa brasileira não é tão livre quanto parece, não é o jornal que falha nisso, é a imprensa brasileira que sofre disso. A questão de defender interesses é uma coisa para nós antiética, mas estamos fazendo parte de uma indústria de informações e isso é nacional - o que é o ponto mais delicado, porém a realidade é essa. Você pode fazer seu trabalho sem deixar a ética de lado, é só achar o ponto certo para isso (HISATORM, 2012).
\end{abstract}

A visão expressada pelo profissional a respeito do alinhamento político da mídia demonstra sua capacidade de questionar o que são os meios de comunicação hoje no Brasil e qual é o papel do jornalismo. Na pesquisa empreendida com profissionais paulistas, Fígaro (2013, p. 38) apontou como alternativas para identificar o setor: 1) negócio, 2) instrumento de fazer política, 3) instrumento de informação e cultura, 4) negócio diferenciado com função social, 5) o negócio mais promissor do mundo globalizado. "Os jornalistas sindicalizados e os freelancers [...] concordam que a profissão de jornalista está sendo precarizada e, para eles, essa situação tende a aumentar nos próximos anos. As causas são as mudanças no mundo do trabalho e para as empresas pagarem salários menores". E a autora completa: "Apenas os profissionais

\footnotetext{
${ }^{8}$ A entrevista com o jornalista foi feita pela acadêmica Marcela Andressa da Silva, em um trabalho de iniciação científica orientado pelo professor Emerson Castro, da Universidade Positivo, em 2012.
} 
do grupo B [os que trabalham em grandes veículos de comunicação] veem a informação como um direito do cidadão; os demais a consideram como produto fundamental na sociedade" (idem, p. 39).

A editora de economia do Bem Paraná/Jornal do Estado, Ana Ehlert ${ }^{9}$, é a única responsável pelo noticiário econômico do jornal e do site. Sem auxílio de repórteres próprios, ela informa que utilizada matérias vindas de agências de notícias e assessorias de imprensa, ou trabalha temas que podem ser adiantados e apurados fora do ritmo "normal" de trabalho do dia a dia. A editoria de economia não possui paginação fixa há três anos, dessa forma as matérias são publicadas em páginas diferentes de acordo com o tema abordado. A editora também é encarregada de fechar as páginas especiais de negócios, consumidor, informática e carro, que circulam uma vez por semana, em diferentes edições.

Desde que a redação do jornal passou por um processo de redução, tanto de espaço físico quanto do número de funcionários, não há mais uma reunião de pauta em que diariamente os jornalistas discutam e planejem a edição. Atualmente, cada editor é responsável pela procura de pautas de sua editoria. A editora de economia busca temas para apuração principalmente na internet, sobretudo nas redes sociais, e nos releases de assessorias de imprensa. Apesar do jornal não possuir uma linha editorial muito rígida, Ehlert diz a cobertura de economia se propõe a abordar a chamada "economia popular", voltada especificamente para o consumidor.

Os editores de política, Ivan Santos, e de esportes, Lycio Velozo Ribas ${ }^{10}$, igualmente reclamam da falta de pessoal e das dificuldades para fechar uma edição de jornal impresso e atualizar um site com um número tão restrito de profissionais na redação. $\mathrm{Na}$ editoria de esportes trabalha apenas um repórter que cobre os principais fatos envolvendo os times de futebol de Curitiba. Todo o restante do material publicada vem de agências e assessorias.

Velozo, além de editar esportes, cuida também do fechamento da primeira página e precisa contar com a colaboração dos editores das demais áreas na elaboração das chamadas de primeira, títulos e legendas de fotografias. "É um processo que sobrecarrega as duas funções, mas é o possível", disse ele, acrescentando que as pressões vêm de todos os lados e são de diversos gêneros; há um alto grau de estresse por razões específicas da editoria - por exemplo, os jogos de futebol encerrados por volta das 23 horas cujas coberturas precisam ser feitas velozmente para evitar atrasos na impressão do jornal. Apesar de todas as dificuldades, ele disse

\footnotetext{
${ }^{9}$ A jornalista foi entrevista pela estudante Ana Carolina Vieira Kruger, em um trabalho de iniciação científica orientado pelo professor Emerson Castro, da Universidade Positivo, em 2012.

${ }^{10}$ Ivan Santos foi entrevistado pela acadêmica Pamela Castilho Ehene e Lycio Velozo por Carolina Pereira, ambas orientadas no trabalho de iniciação científica pelo professor Emerson Castro, em 2012.
} 
que existe cooperação permanente, sobretudo no fechamento. "Há interação durante o processo de apuração, existe a criatividade que enriquece e dá satisfação de ver resultado e há relações de amizade extrapolam o dia a dia de trabalho" (VELOZO, 2012).

De acordo com a chefe de redação, Josianne Ritz, são estas relações de amizade e o fato de todos os profissionais trabalharem juntos há mais de uma década que sustentam o ritmo de produção na redação do Bem Paraná. "Hoje o jornalista sofre um nível de pressão no trabalho muito maior. É muita informação circulando o tempo todo e muita inovação técnica aparecendo constantemente. O jornalista precisa se mexer, pois se não morre profissionalmente", disse ela. Ritz defende que o profissional hoje precisa saber, pelo menos o básico, de web design, além de conhecer os mecanismos de postagens nos sites. Além disso, ela questiona as divisões de editorias e prevê que, cada vez mais, os profissionais serão multitarefas e capazes de cobrir todos os setores: "Talvez as editorias de esporte e política mantenham suas especificidades, mas creio que a geral vai absorver cada vez mais conteúdos” (RITZ, 2014).

O sociólogo norte-americano Warren Breed descreve, em estudo elaborado em 1955, o contexto profissional-organizativo-burocrático que exerce influência decisiva nas escolhas dos jornalistas. Um conjunto de mecanismos de punição e recompensa foi identificado como capaz de promover o conhecimento e a aceitação dos limites organizacionais por parte dos jornalistas em cada local de trabalho. Pena (2006, p. 136/137) sintetiza estes mecanismos:

- autoridade institucional e sanções (distribuição das pautas, edição, alterações nos textos, assinatura etc.);

- sentimento de dever e estima para com os chefes;

- aspirações de mobilidade profissional;

- ausência de fidelidade de grupo contrapostas;

- caráter prazeroso da atividade (cooperação no trabalho);

- notícia como valor maior (une interesses chefias e profissionais - trabalho constante e desafiador): é na atividade de buscar notícias que os jornalistas "investem tempo, em vez de contestar a linha editorial da empresa. A harmonia entre os jornalistas e seus superiores é sedimentada pela realização do trabalho comum a ambos: obter notícias” (PENA, 2006, p. 137).

O mesmo estudo aponta, por outro lado, fatores que indicam a relativa autonomia dos jornalistas que podem, pelo menos parcialmente, "fugir do controle social da empresa" (idem). São eles: as normas da política editorial nem sempre são claras (aprende-se por “osmose”) e os jornalistas podem alegar desconhecimento dos limites empresariais quando publicam alguma coisa contrária ao interesse patronal; os profissionais têm uma margem de "autonomia própria", sobretudo os repórteres especializados em determinadas coberturas ou editorias; em último 
caso, os jornalistas podem passar a informação para a concorrência e "forçar" a publicação da notícia também no veículo para o qual trabalham.

De acordo com Breed (1993), os jornalistas conhecem a política editorial das empresas onde atuam. Ele descreve que se dá "por osmose" o processo por intermédio do qual os profissionais tomam conhecimento desta política, descobrindo e interiorizando os direitos e obrigações de sua função, bem como seus valores e regras:

Todos, com exceção dos novos, sabem qual é a política editorial. Quando interrogados, respondem que a aprenderam "por osmose". Em termos sociológicos, isso significa que se socializaram e "aprenderam as regras" como um neófito numa subcultura. Basicamente, a aprendizagem da política editorial é um processo através do qual o novato descobre e interioriza as obrigações e direitos do seu estatuto. Aprende a antever aquilo que se espera dele, a fim de obter recompensa e evitar penalidades (BREED, 1993, p. 155).

Citando Solosli (1993), Jorge Pedro de Sousa (2002) evidencia os constrangimentos organizacionais que pesam sobre o trabalho jornalístico, salientando o caráter adaptativo do processo de internalização dos parâmetros da empresa:

\begin{abstract}
A natureza organizacional das notícias é determinada pela interação entre o mecanismo de controle transorganizacional representado pelo profissionalismo jornalístico e os mecanismos de controle representados pela política editorial. Em conjunto, esses mecanismos de controle ajudam a estabelecer as fronteiras do comportamento profissional dos jornalistas. [...] As fronteiras são suficientemente amplas para permitir aos jornalistas alguma criatividade, e suficientemente estreitas para se poder confiar que os jornalistas agem no interesse da organização jornalística (SOLOSKI, 1993, p. 100, apud SOUSA, 202, p.55/56).
\end{abstract}

Nas falas dos integrantes da redação do Bem Paraná é possível evidenciar estes constrangimentos organizacionais agravados, no período mais recente, pelas pressões advindas das novas dinâmicas do trabalho jornalístico, com sua velocidade ampliada, suas exigências de conhecimento tecnológico e as diversificadas demandas da audiência. O compromisso histórico do jornalismo - com o interesse coletivo, a vigilância do poder, a defesa da democracia e outros fundamentos da profissão - é colocado em xeque nesta conjuntura, como ser verá a seguir.

\title{
Informação Jornalística
}

A chefe de redação do Bem Paraná descreve como "enlouquecedor” o acompanhamento diário que faz dos mecanismos de aferição das visualizações no portal de notícias. "Você sabe o que as pessoas estão vendo naquele momento e quais as matérias que estão subindo no número de visitantes, ou quais estão sendo compartilhadas. Eu enlouqueço todos os dias porque nem sempre aquilo que está sendo mais visto é o que eu acho mais correto jornalisticamente", admite 
ela. Segundo Fígaro (2013, p.76), "no trabalho com o jornalismo on-line, o tempo verbal do relato é o gerúndio: estão trabalhando, estão apurando, estar produzindo, estar atualizando. Essa fala tem a expressividade do acontecimento, do prolongamento, da continuidade, do nunca terminado do fazer real da atividade e trabalho; não é vício de linguagem, é a capacidade expressiva disponível da língua para o dizer da atividade”.

O grande desafio, para Ritz, é o jornalista não cair no apelativo, no pastelão - "como até os grandes portais nacionais várias vezes fazem". Para contentar o público dos 8 aos 80 anos, ela tem apostado em duas estratégias: foco no noticiário local e em temáticas menos pesadas, que comportem a possibilidade de serem abordadas com certa dose de humor, que busquem mostrar situações inusitadas e até bizarras, mas sem apelação ou sensacionalismo. "Tenho puxado as orelhas da minha equipe para que tenhamos maior criatividade nas pautas e nas abordagens. $\mathrm{Na}$ internet existe absolutamente de tudo, precisamos um diferencial. Não podemos envelhecer profissionalmente" (RITZ, 2014).

O não envelhecimento profissional está calcado, sobretudo, na capacidade de vibrar com a notícia, de se comprometer com a informação factual - o que é ainda mais necessário no jornalismo online. "Quem gosta desta vibração do acontecimento virando notícia não consegue se desligar. É ótimo dar uma informação em primeiro lugar” (RITZ, 2014). Por outro lado, a internet está forçando uma reflexão diária a respeito do fazer jornalístico, “que está se transformando de uma maneira muito veloz e, na maior parte das vezes, não temos certeza em qual direção caminha" (idem).

Roseli Fígaro (2013) debate esta questão da informação na pesquisa que empreendeu com profissionais de São Paulo. Ela cita uma entrevistada que relaciona as mudanças no mundo do trabalho profissional e a visão sobre informação:

É uma questão complexa que remete à discussão da informação como produto para consumo e informação como direito do cidadão; explicita o fascismo existente no traçado de público-alvo como média. Ao manter a justificativa da pauta a ser publicada pelo viés de público-alvo traçado pelo marketing, a empresa deixa de fazer jornalismo. Acontece aí, no mundo do trabalho, o embate concreto que começa nas escolhas cotidianas sobre a pauta, o que aparece como notícia e o que não aparece. No microcosmo do mundo do trabalho se digladiam os pontos de vista, as ideologias, e os problemas da cidade. É na atividade de trabalho que se constrói a sociedade (FÍGARO, 2013, p. 61).

Na redação do Bem Paraná várias apostas têm sido feitas no sentido de buscar determinar o quê o público busca, que tipo de informação faz sucesso. "E temos conseguido comprovar que pautas bem elaboradas, bem apuradas e bem escritas sobem [têm maior número de acessos no site]. Não queremos aceitar o antijornalismo, a fofoca barata. Dá agonia, aquelas 
informações sem qualquer qualidade não podem vencer a gente, podemos oferecer coisa melhor, que faça diferença para a sociedade" (RITZ, 2014).

Com 19 anos de trabalho na redação do Bem Paraná, Josianne Ritz confessa que se interroga a respeito da possibilidade de sobrevivência do jornal impresso, ao mesmo tempo em que teme pelo jornalismo na internet: "Tenho medo que o online vire uma coisa de estagiários, que fiquem apenas copiando e colando informações de variadas origens, muitas vezes sem credibilidade". Ela acredita que a profissão, cujas bases essenciais não foram alteradas, ainda exige paixão:

\begin{abstract}
A informação que damos à sociedade tem condições de influenciar na vida das pessoas. Por isso é inaceitável a informação errada, deturpada. Mesmo com todas as mudanças nos processos produtivos do jornalismo, não mudou a responsabilidade de apurar bem. O começo da notícia mudou, pois hoje sabemos dos fatos pelas redes sociais, mas o final da notícia persiste: tem que ser apurada corretamente. Mudou também o texto, a forma de escrever tem que ser mais breve, já que as pessoas não têm paciência para ler textos longos, mas o compromisso em escrever corretamente, em bom português, persiste. E não mudou a capacidade de observação que é típica do jornalista: temos que olhar para todos os lados o tempo todo em busca de pautas. A partir do momento em que nos fecharmos no nosso mundinho, nos burocratizamos, envelhecemos e morremos profissionalmente (RITZ, 2014).
\end{abstract}

De acordo com Fígaro (2013, citando Ianni, 1995), há um conjunto de fatores históricos, políticos e econômicos que dizem respeito aos dilemas vividos nas décadas de 1980/90, com relação à crise do socialismo real, o neoliberalismo e o globalismo que interferiram na formação das jovens gerações de jornalistas. Essa conjuntura conforma e dá forma aos usos da tecnologia da informação e da comunicação nos negócios, na escola, na cidade. Como artefatos de cultura e instrumentos de uso no cotidiano (FOLCHER; RABARDEL, 2007, apud FÍGARO, 2013), a partir dessa conjuntura, as tecnologias de comunicação e informações redesenharam o mundo do trabalho, sobretudo, o trabalho do jornalista.

Desafio para as novas gerações que trazem o conhecimento tácito do uso da tecnologia e se deparam, no trabalho, com outra geração que não tem esse conhecimento tácito. Esse encontro, muitas vezes desencontro, tem de ser administrado no momento da atividade. $\mathrm{O}$ conjunto de regras, normas editoriais, fundamentos éticos desenvolvidos ao longo dos anos vão se encontrar com os novos artefatos tecnológicos e, ambas as gerações, têm de (re)aprender a fazer jornalismo a partir deles e com eles. No entanto, "os valores que orientam o que é notícia não mudaram por causa das tecnologias, mudaram porque a lógica do mercado invadiu todas as esferas da vida social" (FÍGARO, 2013, p. 63).

\title{
Considerações finais
}


Os relatos dos jornalistas do jornal e do portal Bem Paraná, uma redação de porte pequeno localizada em uma cidade relativamente periférica como Curitiba, são capazes de exemplificar as mudanças ocorridas no mundo do trabalho dos jornalistas e de levantar questionamentos sobre o futuro da profissão. Acúmulo de funções, aumento nas horas trabalhadas, jornadas domiciliares e nos finais de semana, pressões pela velocidade de produção e postagem, entre outros, são aspectos relatados pelos profissionais que confirmam a degradação das condições de trabalho. A existência de parceria entre o portal e um repórter/blogueiro da área policial corrobora a precarização das relações de trabalho, a exemplo do que foi documentado por Fígaro (2013) na cidade de São Paulo.

No caso da redação curitibana, ao lado dos constrangimentos referenciados por autores que trabalham as teorias organizacionais do jornalismo (Breed, Soloski), percebe-se que as relações de amizade e companheirismo, consolidadas em dez ou quinze anos de trabalho compartilhado, sustentam a rotina e reduzem os desgastes profissionais e pessoais que seriam legítimos supor em um ambiente de trabalho tão restrito e potencialmente tenso.

Ademais, parece claro nos depoimentos dos integrantes da redação Bem Paraná que transcendendo a batalha pela manutenção dos próprios empregos e da própria sobrevivência há uma preocupação com o caráter social da atividade jornalística. Os profissionais citam os reflexos dos compromissos políticos/econômicos das empresas, a pressão da audiência que nem sempre valoriza a informação socialmente mais relevante, o risco da espetacularização e outros obstáculos ao bom desempenho do jornalismo. Tudo isso envolto na problemática maior determinada pelo advento das novas tecnologias que alteraram o dia a dia da profissão.

Nesta etapa histórica de oscilação e incógnita, o exemplo apresentado neste texto pode, eventualmente, apontar alguns indícios e colaborar para ampliar os questionamentos que nos auxiliem, enquanto jornalistas e pesquisadores, a compreender as mudanças que estão se processando no fazer jornalístico da contemporaneidade.

(Artigo recebido em 05/12/2014, aprovado em 20/12/2014)

\section{Referências}

BREED, W. Controlo social na redacção. Uma análise funcional. In: TRAQUINA, Nelson (org.). Jornalismo: questões, teorias e "estórias". 2 ed. Lisboa: Vega,1993.

FIGARO, Roseli (org.); NONATO, Cláudia; GROHMANN, Rafael. As mudanças no mundo do trabalho do jornalista. São Paulo: Salta, 2013.

PENA. F. Teorias do Jornalismo. São Paulo: Contexto, 2006.

OLIVEIRA FILHA, Elza A. Olhares sobre uma cobertura: a eleição de 2002 para o governo do Paraná em três jornais locais. Curitiba: Pós-escrito, 2007. 
DITO EFEITO - ISSN 1984-2376 - v. 5, n. 7, jul./dez. 2014 - UTFPR CURITIBA - http://periodicos.utfpr.edu.br/de

SOUSA, J. P. Teorias da notícia e do jornalismo. Chapecó: Argos, 2002. 